\title{
AVANCE DE LOS RESULTADOS DE LA CAMPAÑA DE DOCUMENTACIÓN ARQUEOLÓGICA EN LA NECRÓPOLIS MEGALÍTICA DE LA LENTEJUELA (TEBA-MÁLAGA)
}

\section{ADVANCE OF THE RESULTS OF THE ARCHAEOLOGICAL DOCUMENTATION CAMPAIGN AT THE MEGALITHIC NECROPOLIS OF LA LENTEJUELA (TEBA-MALAGA)}

\section{Serafín BECERRA MARTÍN ${ }^{1 *}$, Eduardo VIJANDE VILA², Alejandro MUÑOZ MUÑOZ², María Leticia GÓMEZ SÁNCHEZ², Diego Salvador FERNÁNDEZ SÁNCHEZ² , Adolfo MORENO MÁRQUEZ ${ }^{3}$, Juan Jesús CANTILLO DUARTE ${ }^{2}$, José Luis RAMÍREZ AMADOR ${ }^{2}$, Laura PAVÓN GONZÁLEZ ${ }^{2}$ y José Juan DÍAZ RODRÍGUEZ ${ }^{2}$}

\author{
${ }^{1}$ Doctor, Grupo HUM-440. IES Itaba, calle Extramuros s/n, Teba, Málaga \\ * Correo electrónico: serafinbecerramartin@gmail.com \\ ${ }^{2}$ Universidad de Cádiz \\ ${ }^{3}$ Universidad de Almería
}

\begin{abstract}
Resumen: Con motivo de la campaña de prospección y documentación digital desarrollada en la necrópolis megalítica de La Lentejuela durante el mes de julio de 2021 presentamos un avance de los resultados. La aplicación de nuevas técnicas de registro arqueológico como el escáner 3D o la fotogrametría ha permitido documentar con mayor resolución un yacimiento con gran potencial para el conocimiento del megalitismo en la región.
\end{abstract}

Palabras Clave: Arquitectura megalítica, Prehistoria reciente, valle del Guadalteba, tecnología digital, escaneo 3D, fotogrametría.

\begin{abstract}
On the occasion of the prospecting and digital documentation campaign developed in the megalithic necropolis of La Lentejuela during July 2021, we present a preview of the results. The application of new archaeological record techniques such as 3D scanning or photogrammetry has made it possible to document with higher resolution a site with great potential for the knowledge of megalithism in the region.
\end{abstract}

Keywords: Megalithic architecture, Late Prehistory, Guadalteba valley, digital technology, 3D scanning, photogrammetry.

Sumario: 1. Introducción. 2. Localización del yacimiento. 3. Descripción de los trabajos. 4. Resultados preliminares. 5. Agradecimientos. 6. Bibliografía.

\section{Introducción}

La necrópolis megalítica de La Lentejuela se documentó por primera vez en el año 1991 durante una prospección del Servicio de Arqueología de la Diputación de Málaga en el término de Teba (Recio, 1993). Pero no será hasta comienzos de los años 2000 cuando se investigue con mayor detalle por parte de un equipo de la Universidad de Málaga (en adelante UMA) y la Asociación Hisn Atiba, dirigido por la profesora Ana Baldomero y el investigador José Berdugo. De este modo, entre
2005 y 2008, se lleva a cabo una prospección y documentación del yacimiento, y posteriormente la excavación del sepulcro $\cong 4$ (Baldomero et al., 2005; Baldomero y Berdugo, 2010).

Una década después de los trabajos de la UMA, miembros del Grupo de Investigación PAI HUM440 de la Universidad de Cádiz comenzamos a gestar un nuevo proyecto arqueológico en el yacimiento, que se materializó en un proyecto de "Actividad arqueológica puntual de prospección arqueológica superficial y documentación gráfica" de las estructuras megalíticas. Con fecha de 18 de 
diciembre de 2020 hicimos entrega del citado proyecto que, tras informe favorable de la Delegación Territorial de Cultura y Patrimonio de Málaga, fue autorizado con fecha 26 de febrero de 2021 por la Dirección General de Patrimonio Histórico y Documental de la Consejería de Cultura y Patrimonio Histórico de la Junta de Andalucía.

La motivación científica de la actividad vino determinada por la necesidad de llevar a cabo una revisión del conocimiento de la necrópolis con el fin de generar una documentación más completa y actualizada como paso previo a la solicitud de un Proyecto General de Investigación. El gran desarrollo metodológico que ha supuesto para la práctica arqueológica la aplicación de nuevas tecnologías de documentación, como la fotogrametría, el escáner 3D o la implementación de sistemas de información geográfica, hacía imprescindible una nueva intervención que paliara el desfase en cuanto a la información que disponíamos sobre el yacimiento.

En nuestro caso, consideramos que en el estudio de los monumentos megalíticos los nuevos protocolos de documentación permiten representar y captar la realidad volumétrica exacta de estas construcciones, generándose estudios más exhaustivos y menos invasivos en comparación con el trabajo de campo tradicional, como se ha demostrado en otras necrópolis megalíticas (Benavides et al., 2016).

\section{Localización del yacimiento}

El enclave arqueológico de La Lentejuela se sitúa dentro del término municipal de Teba, a unos $5 \mathrm{~km}$ del casco urbano, en las estribaciones de la sierra homónima, concretamente en el paraje extremo suroccidental conocido como La Patrana. El acceso se realiza desde la cañada real de Ronda a Granada, donde hay que tomar un desvío por el camino que llega al cortijo de Vacablanca, para proseguir unos 800 metros en dirección oeste hasta la necrópolis (Figura 1).

En términos geológicos el yacimiento se enclava sobre calizas, margocalizas y margas del penibético de edad jurásico-cretácica, localizándose algunas estructuras megalíticas en la zona de contacto con las arcillas pertenecientes al complejo Campo de Gibraltar (Cruz-Sanjulián, 1990). Tradicionalmente, la roca caliza de la sierra ha sido explotada mediante canteras de piedras de molino, lo que ha alterado la morfología originaria del terreno y pudo haber afectado negativamente a algunas construcciones megalíticas.

El cerro de La Patrana se constituye como un balcón natural que domina la parte alta y central del valle del Guadalteba, divisándose desde su cima un imponente paisaje y un amplio territorio de sierras y campiña.

\section{Descripción de los trabajos}

El diseño de las estrategias y aplicaciones metodológicas que hemos desarrollado en esta actividad arqueológica se orientaron a cumplir con los objetivos que nos planteamos, entre los que estaban desarrollar un análisis espacial arqueológico detallado y documentar a gran resolución las estructuras que componen la necrópolis.

Para conocer de primera mano el ámbito territorial del yacimiento, realizamos una prospección superficial en un área de 400 hectáreas, en el polígono propuesto para su protección como Bien de Interés Cultural (unas 48 ha.) llevamos a cabo una exploración intensiva. En el caso de esta prospección intensiva, efectuamos un recorrido lineal y en paralelo sobre el terreno con bandas de prospección de $10 \mathrm{~m}$ de anchura, mientras que en la de carácter extensivo la distancia entre personas fue de 20 metros. Durante los trabajos nos encontramos con sectores de orografía abrupta, con presencia de cortados y promontorios acusados donde las precauciones fueron máximas, y zonas extensas de campiña.

Durante la prospección localizamos dos nuevos sepulcros megalíticos, que al igual que los ya conocidos fueron georreferenciados utilizando un GPS móvil.

En una segunda fase de la intervención en campo procedimos a limpiar de vegetación el área circundante de cada uno de los megalitos para realizar una buena documentación gráfica mediante fotogrametría y escáner 3D, así como un levantamiento topográfico detallado. Para la ejecución de estos trabajos contamos con materiales pertenecientes al Laboratorio de Arqueología y Prehistoria (LABAP) de la Universidad de Cádiz.

Para conseguir una mayor resolución a la hora de desarrollar los análisis espaciales consideramos imprescindible realizar un nuevo levantamiento topográfico, lo que nos ha permitido disponer de una cartografía de gran precisión, zonas de detalle con curvas de nivel para cada 20 centímetros y otra más 


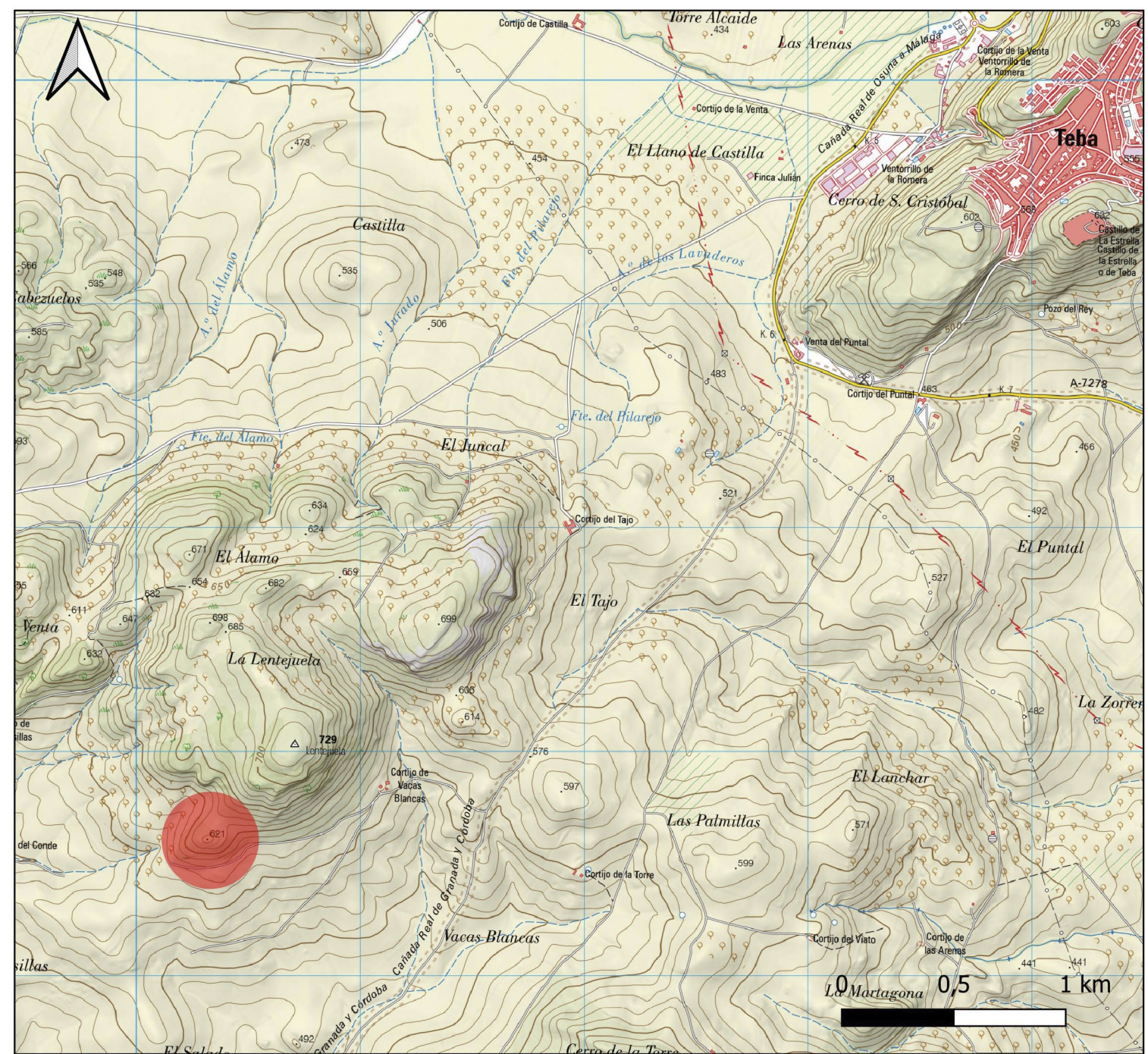

Figura 1. Mapa de localización del yacimiento (punto rojo).

general con curvas cada metro. En el levantamiento arqueológico-topográfico se empleó el método RTK y el uso de fotografía aérea mediante dron, con lo que hemos determinado la localización exacta, la distribución y dispersión de los megalitos en la necrópolis, así como establecidas zonas en función de la concentración de estas construcciones.

En el trabajo de escaneo empleamos el Láser escáner 3D Leica RTC360 (Figura 2), un equipo que permite documentar y capturar entornos en 3D con gran precisión de forma no intrusiva. Este equipo también toma imágenes de alto rango dinámico (HDR), consiguiendo un mayor realismo. La fotogrametría ha sido realizada mediante dos técnicas de registro fotográfico, por un lado la manual, y por otro la toma de imágenes mediante dron. En el caso de la toma de imágenes con cáma- ra fotográfica manual, esta se realizó desde diferentes perspectivas para obtener todos los puntos de visión posibles.

Las ventajas de este tipo de documentación es que en escaso tiempo hemos podido obtener una gran cantidad de información a nivel constructivo (dimensiones, secciones, plantas, etc.), la cual almacenamos y comparamos con otros modelos generados.

\section{Resultados preliminares}

En primer lugar, tenemos que señalar que valoramos positivamente los resultados obtenidos en la actividad arqueológica, especialmente el registro digital de las estructuras. Las técnicas empleadas nos han permitido generar un corpus de do-

Revista Atlántica-Mediterránea de Prehistoria y Arqueología Social 23, pp. 189-194 


\section{NOVEDADES}

Revista Atlántica-Mediterránea 23, pp. 189-194

BIBLID [2445-3072 (2021) 23, 1-239]

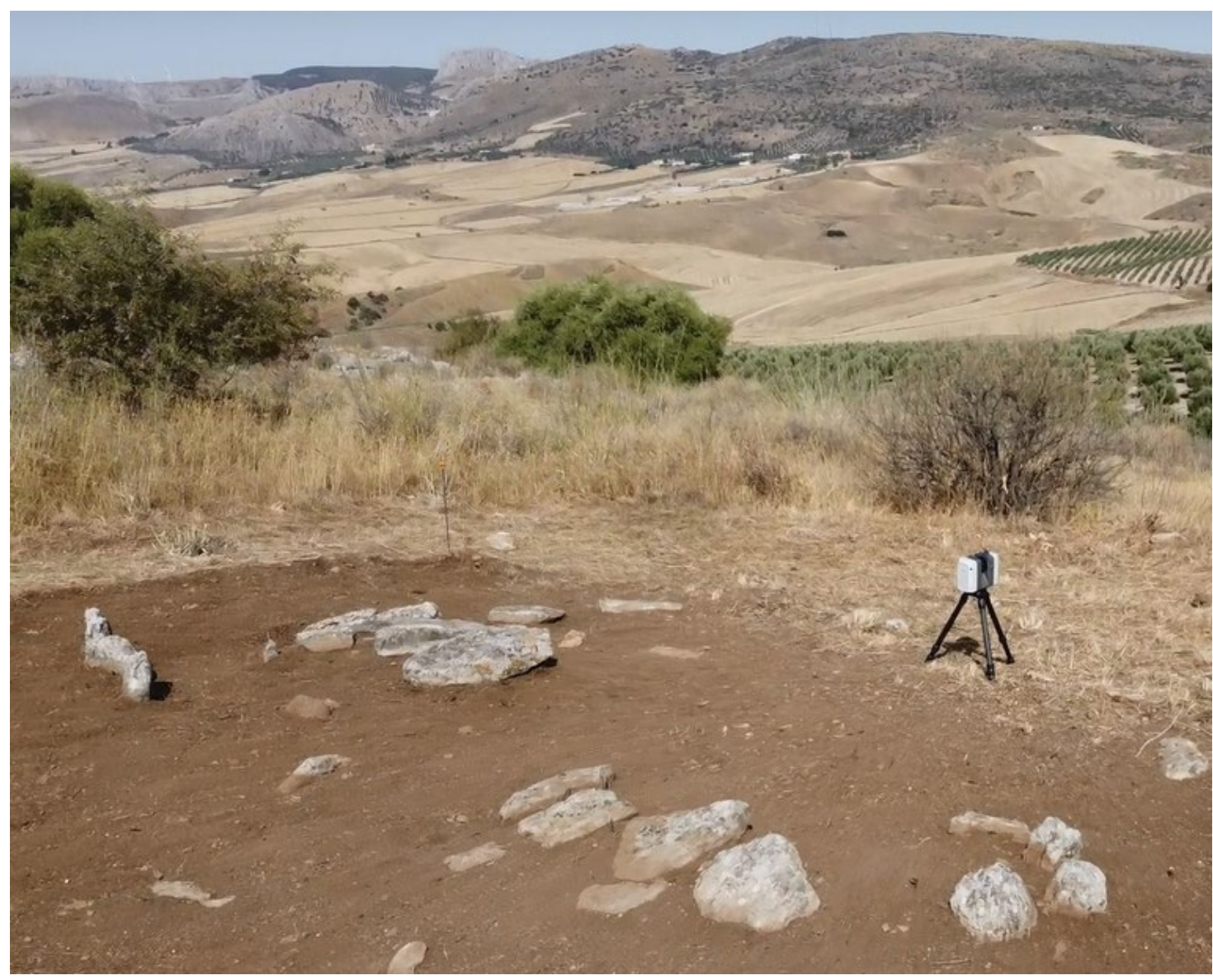

Figura 2. Instantánea de la documentación mediante escáner 3D.

cumentación de gran realismo y precisión, lo que nos ha ayudado a conocer mejor la potencialidad del yacimiento y permitirá una planificación más detallada de cara a futuras intervenciones.

De las actuaciones precedentes a la que aquí presentamos contábamos con una información limitada, acorde con los desarrollos técnicos de la práctica arqueológica del momento. Por tanto, el trabajo desarrollado en esta actividad no solo complementa a los existentes, sino que ha actualizado y ampliado el conocimiento de la necrópolis (Figura 3).

Podemos avanzar que, el número de estructuras que componen la necrópolis se ha visto incrementado con el hallazgo de dos nuevas construcciones megalíticas. En la actualidad, la necrópolis de La Lentejuela, con un total de 9, puede ser considerada la mayor concentración de sepulcros megalíticos de la provincia de Málaga. Esta agrupación se da en un área relativamente pequeña, apenas 6 hectáreas, a diferencia de otras necrópolis que abarcan una mayor superficie y un menor número de megalitos (Márquez, 2000).

Principalmente se trata de sepulcros de galería de dimensiones modestas, entre 3 y 7 metros de longitud por $1 \mathrm{~m}$ de ancho, y orientadas predominantemente al este. Las estructuras están realizadas con lajas de caliza de mediano y gran formato, el material pétreo con el que construyen aflora en las proximidades de los monumentos en forma de bancos de algunas de decenas de centímetros de espesor, lo que facilitó su extracción.

Destacan dentro del conjunto por su monumentalidad dos estructuras (E1 y E2), ambas están conformadas por un doble anillo peristáltico y una posible cámara funeraria en su interior. Las dimensiones documentadas sobrepasan lo registrado en las demás construcciones del yacimiento, ya que los anillos alcanzan los diez metros de diámetro y la cámara interior pueden tener más de una decena de metros. Su localización en la ladera sur, a escasos metros la una de la otra, dotan de mayor complejidad este conjunto, un espacio que pudo tener una monumentalidad aún más destacada a tenor del gran número de grandes piedras que aparecen dispersas por la zona y que parecen pertenecer a estas construcciones.

Finalmente, quisiéramos concluir comentando 


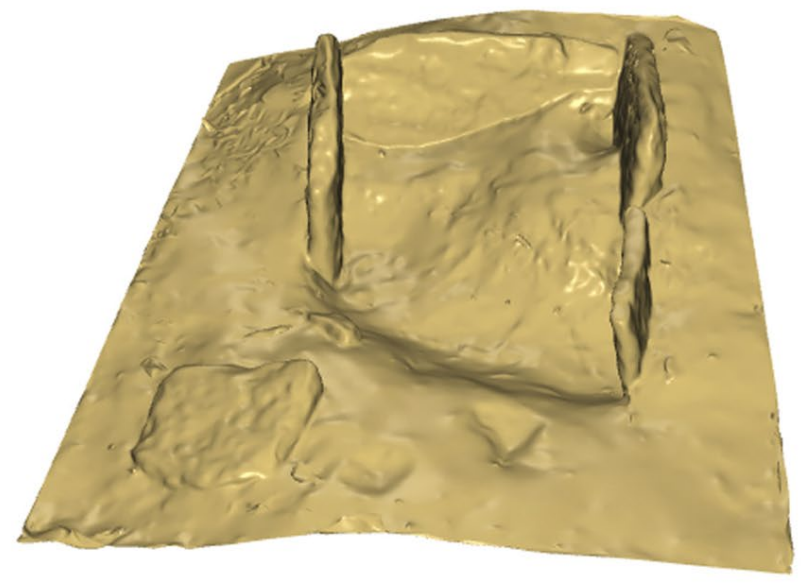

A

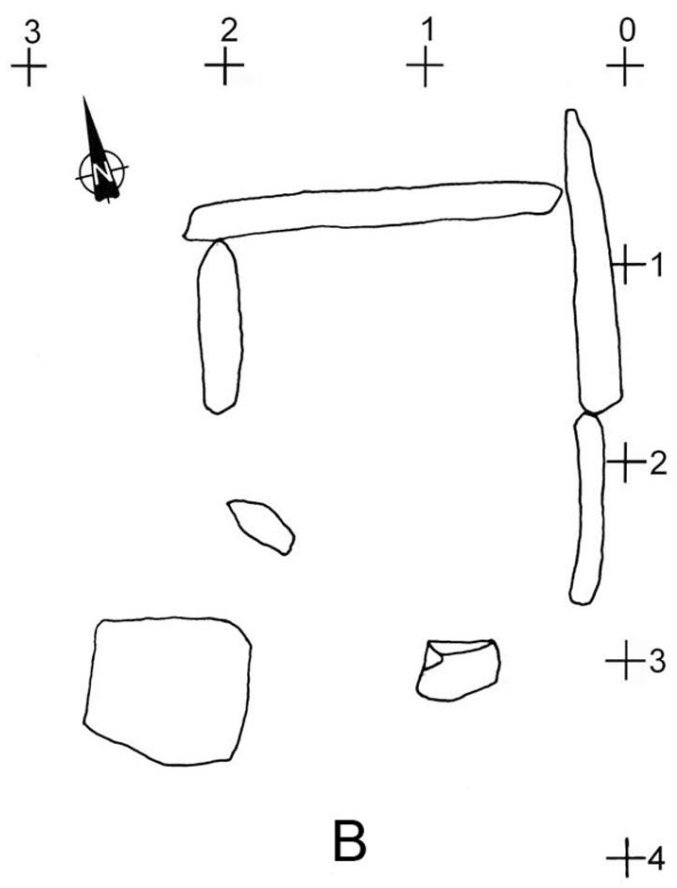

Figura 3. Resultados del escaneo 3D de la Estructura 7 frente a la información obtenida mediante dibujo tradicional.

el papel que jugó la necrópolis megalítica de La Lentejuela (Figura 4) como espacio central de las prácticas funerarias que desarrollaron las comunidades tribales neolíticas y calcolíticas en el valle del Guadalteba durante la Prehistoria reciente (Becerra, 2019; García et al., 1995). Un conjunto megalítico que estructura un territorio definido por el Guadalteba, que se complementa con otros dólmenes de la zona como el de Las Dos Hermanas en Cañete la Real o los de Santiago I y II en Serrato (Becerra, 2015), y a su vez se sitúa a caballo entre el conjunto megalítico de Antequera y la concentración dolménica de la Serranía de Ronda (Márquez, 2000).

\section{Agradecimientos}

Queremos expresar nuestro sincero agradecimiento al Excmo. Ayuntamiento de Teba, entidad que ha financiado la mayor parte de la actividad. A los voluntarios/as que nos acompañaron durante la campaña: María del Carmen Sayago García, Jesús Campos Burgos y Juan Carlos Escalante. Del mismo modo, no podemos dejar de reconocer el apoyo brindado por el Consejo Municipal de Patrimonio Histórico de Teba y a la Asociación para la Defensa del Patrimonio Histórico de Teba Hisn Atiba, especialmente a José Berdugo Romero por la información facilitada.
Agradecer a la Delegación Territorial de Cultura y Patrimonio de Málaga y a la Dirección General de Patrimonio Histórico y Documental de la Consejería de Cultura y Patrimonio Histórico de la Junta de Andalucía por la aprobación del proyecto de actividad arqueológica. A la arqueóloga-inspectora doña María Eugenia García Pantoja sus indicaciones para el buen desarrollo de los trabajos.

Finalmente, mencionar a otros compañeros del equipo de investigación como José Suárez Padilla y Lidia Cabello, y a los profesores José Ramos y Salvador Domínguez-Bella por sus consejos, gestiones y asesoramiento.

\section{Bibliografía}

BALDOMERO, Ana; BERDUGO, José; FERRER, José Enrique. 2006: "La necrópolis megalítica de la Lentejuela, Teba (Málaga)". En P. CANTALEJO (coord.): Actas I Jornadas de patrimonio en la Comarca de Guadalteba: Arte rupestre y sociedades prehistóricas con expresiones gráficas. Centenario de los descubrimientos del arte prehistórico en Málaga (1905-2005), pp. 231-234. Málaga.

BALDOMERO, Ana; BERDUGO, José. 2010: "Prospecciones en el entorno de la necrópolis megalítica de La Lentejuela, Teba (Málaga): 


\section{NOVEDADES}

Revista Atlántica-Mediterránea 23, pp. 189-194

BIBLID [2445-3072 (2021) 23, 1-239]

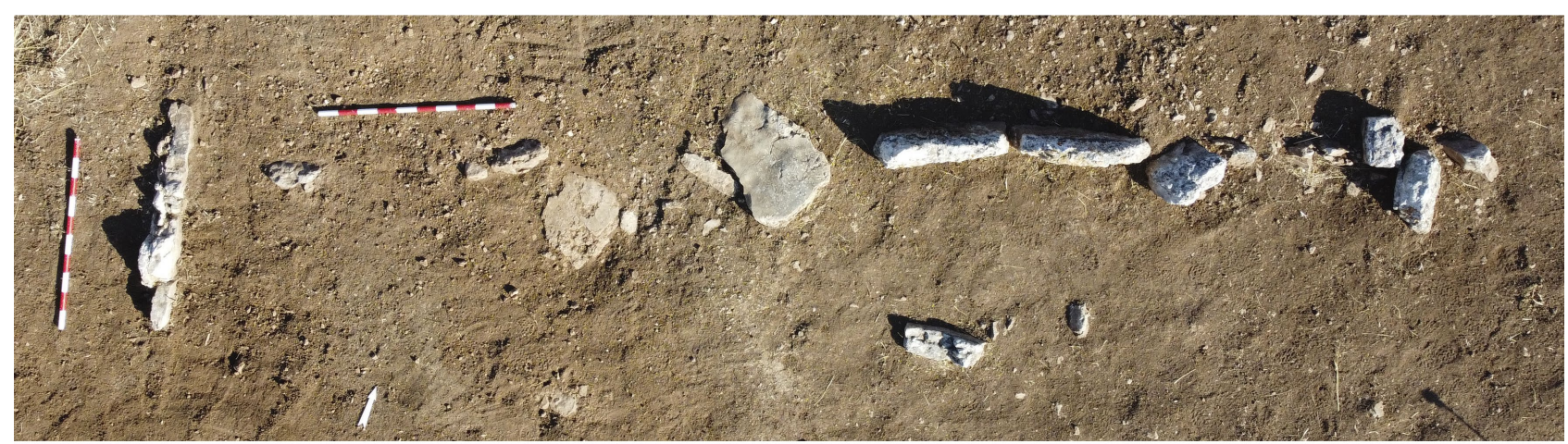

ESTRUCTURA 3

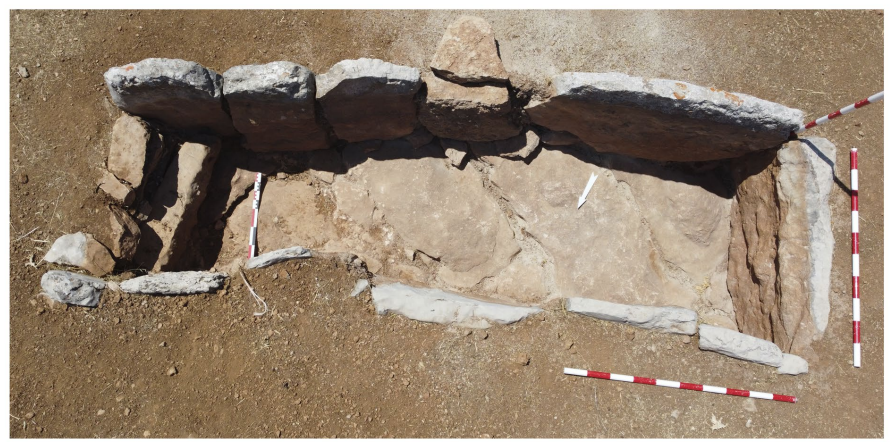

ESTRUCTURA 4

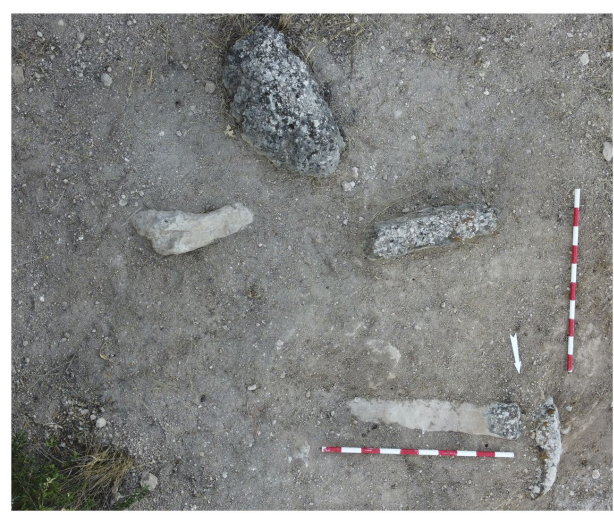

ESTRUCTURA 8

Figura 4. Imágenes de algunos de los dólmenes que componen la necrópolis.

Campaña de actuaciones en el 2005". Anuario Arqueológico de Andalucía/2005, pp. 24832488. Junta de Andalucía. Sevilla.

BECERRA MARTÍN, Serafín. 2015: "De las sociedades tribales a las clasistas iniciales en el territorio de los ríos Guadalteba y Turón (Vo al IIo milenio a.n.e.)". Revista Atlántica-Mediterránea de Prehistoria y Arqueología Social, 17, pp. 135-147.

BECERRA MARTÍN, Serafín. 2019: El aprovisionamiento de sílex durante la Prehistoria reciente en la comarca del Guadalteba (Málaga): Un análisis desde la arqueometría y la tecnología. BAR International Series 2920.

BENAVIDES, José Antonio; ARANDA, Gonzalo; SÁNCHEZ, Margarita: ALARCÓN, Eva; FERNÁNDEZ, Sergio; LOZANO, Águeda; ESQUIVEL, José Antonio. 2016: "3D modelling in archaeology: The application of Structure from Motion methods to the study of the megalithic necropolis of $\mathrm{Pa}$ noria (Granada, Spain)". Journal of Archaeological Science: Reports, 10, pp. 495-506.

CARO, José Luis; HANSEN, Salvador. 2015: "De la fotogrametría a la difusión del patrimonio ar- queológico mediante game engines: Menga un caso de estudio". Virtual Archaeology Review, 6 (12), pp. 58-68.

CRUZ- SANJULIAN, José Javier. 1990: Mapa geológico de España. Teba. Hoja 1037. Instituto Geológico y Minero de España. Madrid.

GARCÍA, Eduardo; FLORIDO, Daniel; PEZZOLI, Federica; GAZZI, Gilberto. 2016: "Drones y su aplicación en arqueología. Volando sobre Acinipo (Ronda, Málaga)". MENGA, 7,pp. 135-153.

GARCIA, Eduardo; MARTÍNEZ, Virgilio; MORGADO, Antonio. 1995: El bajo Guadalteba (Málaga): Espacio y poblamiento. Una aproximación arqueológica a Teba y su entorno. Ayuntamiento de Teba y Diputación provincial de Málaga.

MARQUEZ ROMERO, José Enrique. 2000: El Megalitismo en la Provincia de Málaga. Breve Guía para su Conocimiento e Interpretación. Universidad de Málaga.

RECIO RUIZ, Ángel. 1993: "Informe arqueológico del Término Municipal de Teba (Málaga)". Anuario Arqueológico de Andalucía/1991. Tomo III, pp. 413-418. Junta de Andalucía. Sevilla. 